\title{
S-100 negative myxoid neurothekeoma: a new type of neurothekeoma? ${ }^{*}$
}

\author{
Yasmin Gama Abuawad ${ }^{1}$ \\ Andrezza Telles Westin ${ }^{1}$
}

\author{
Maria Isabel Ramos Saraiva ${ }^{1}$ \\ Neusa Yuriko Sakai Valente ${ }^{2}$
}

DOI: http:/ /dx.doi.org/10.1590/abd1806-4841.20176016

\section{Dear Editor}

Neurothekeomas are rare benign dermal tumors, which originate from the peripheral nerve sheath. They are divided into myxoid, intermediate, and cellular types, based on the amount of myxoid matrix and on the immunohistochemical study. We report an unusual S-100 negative case of myxoid neurothekeoma, which is currently described in the literature as a new type of neurothekeoma. A 73-year old male patient presented with an asymptomatic erythematous nodule $(0.8 \times 0.6 \times 0.5 \mathrm{~cm}$ in size $)$ in the right inframandibular region for about a year (Figure 1). Diagnostic hypothesis were adenoid basal cell carcinoma, neurofibroma, and others skin adnexal neoplasms. After surgical excision with 3-mm margins, pathological studies showed multiple nodules of varying sizes, containing abundant mucin and sparse stellate cells in the dermis, consistent with myxoid neurothekeoma (Figure 2). Immunohistochemistry was focally positive for CD-68 and diffusely positive for vimentin, but negative for S-100, CD-10, CD-57, EMA, and GFAP (Figure 3). Histopathological and immunohistochemical findings corroborated the diagnosis of S-100 negative myxoid neurothekeoma, also described as myxoid neurothekeoma cell. The term neurothekeoma was coined in 1980 by Gallagher and Helwig to de- scribe a skin tumor of neural origin. This neoplasm that originates from the sheath of peripheral nerves mainly affects the face and upper limbs of women between the second and third decades of life. It manifests as a solitary and asymptomatic papule or nodule with indolent growth. ${ }^{1}$ Local trauma and high levels of estrogen have been linked to triggering factors. ${ }^{2}$ Differential diagnoses include dermal nerve sheath myxoma, superficial angiomyxoma, melanocytic neoplasms, reticulohistiocytoma and plexiform fibrohistiocytic tumor. Since its initial description, there remains inconsistency

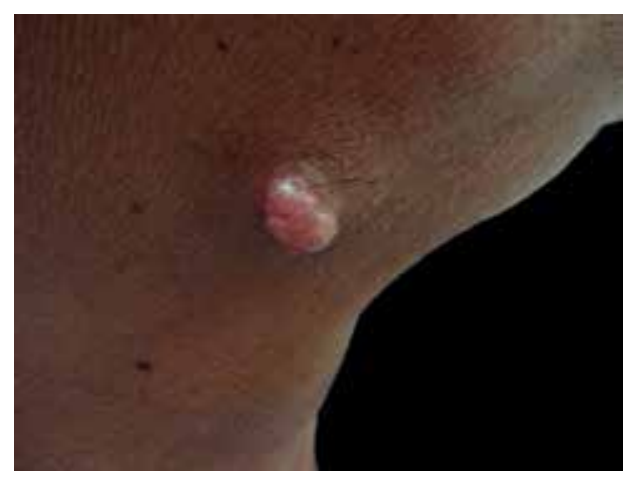

FIGURE 1:

Erythematous nodule in the right inframandibular region
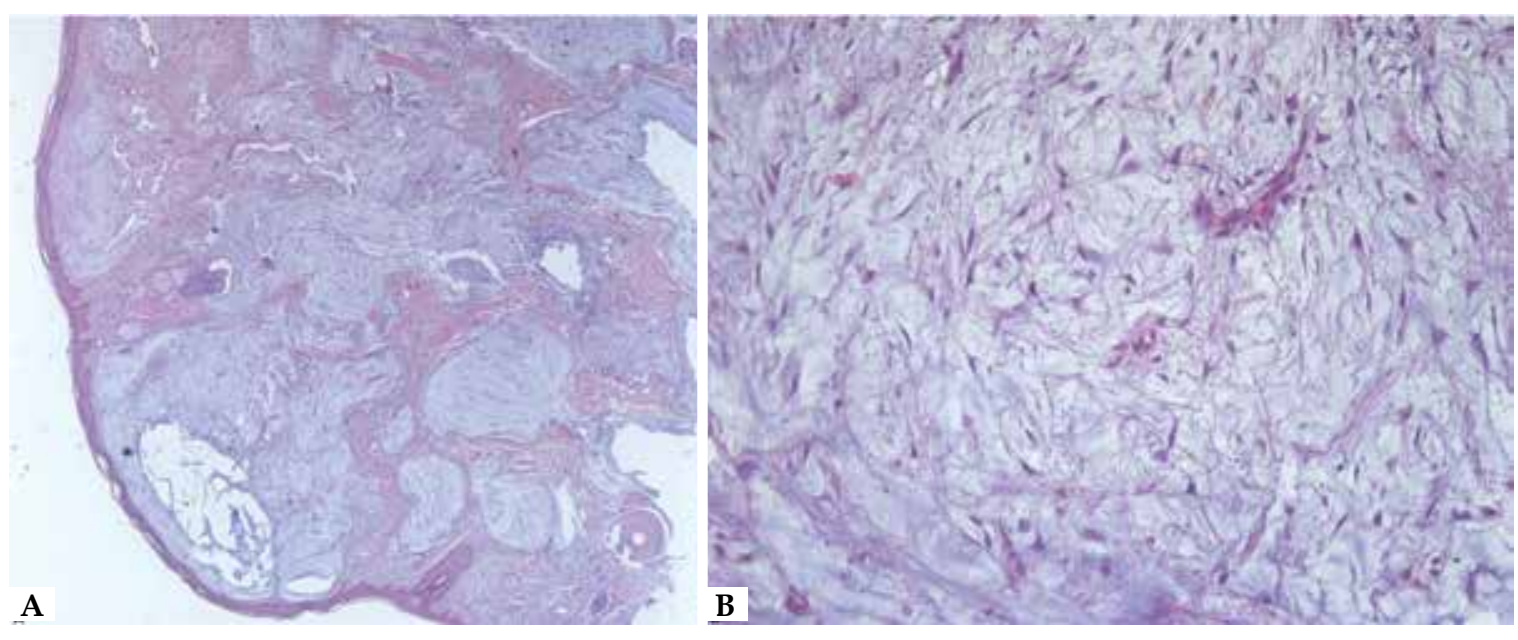

Figure 2:

A) nodules of varying sizes with large amounts of mucin and stellate cells (Hematoxylin \& eosin $\mathrm{x} 20)$; B) detail of stellate cells (Hematoxylin \& eosin $\times 200)$

Received on 09.05.2016

Approved by the Advisory Board and accepted for publication on 11.07.2016

* Work performed at Hospital do Servidor Público Estadual de São Paulo (HSPE/IAMSPE) - São Paulo (SP), Brazil.

Financial Support: None.

Conflict of Interest: None.

Dermatology Service at Hospital do Servidor Público Estadual de São Paulo (HSPE) - São Paulo (SP), Brazil.

Dermatopathology Section and Dermatology Service at Hospital do Servidor Público Estadual de São Paulo (HSPE) - São Paulo (SP), Brazil.

(2017 by Anais Brasileiros de Dermatologia 

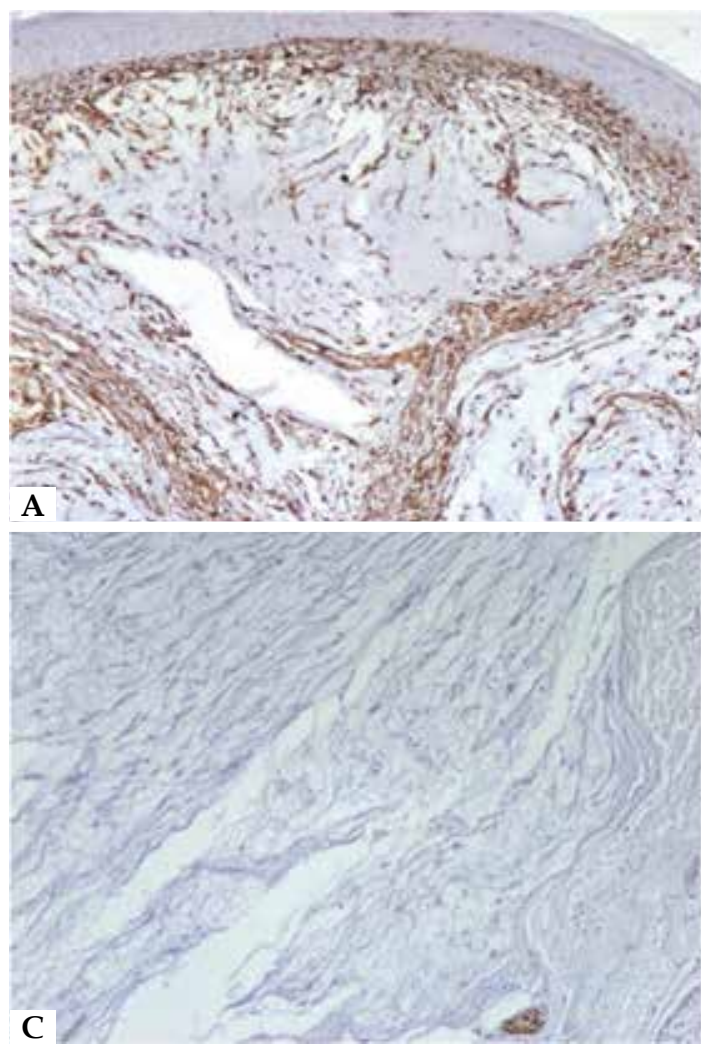
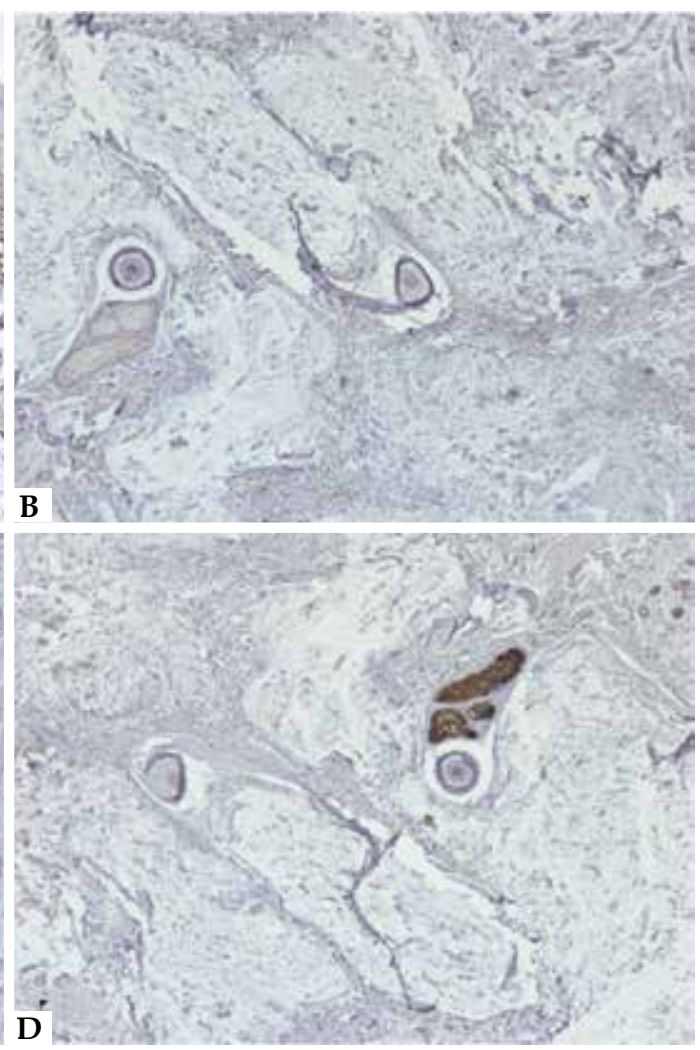

Figure 3:

Immunohistochemistry: A) positivity for vimentin (Hematoxylin \& eosin $x 200)$;

B) positivity for $\mathrm{CD}-68$ (Hematoxylin \& eosin $\mathrm{x} 40$ );

C) negativity for S-100 in tumor cells and positivity in the nerve (Hematoxylin \& eosin $\mathrm{x} 100)$;

D) negativity for EMA (Hematoxylin \& eosin $\mathrm{x} 20)$ regarding the relationship of the tumor with the dermal myxoma of the nerve sheaths. Studies of large case series have shown that they are two distinct entities. ${ }^{3}$ Myxoma also affects men and women, preferably on hands, with higher recurrence rates. Histologically, it appears as superficial multilobular masses, rich in myxoid material, with well-defined fibrous edges and stellate cells, spindle cells, and epithelioid Schwann cells. It demonstrates positivity for S-100 and GFAP. ${ }^{1}$ The myxoid, intermediate, and cellular neurothekeoma subtypes depend on the amount of myxoid matrix and immunohistochemical profile observed. Tumors with $10 \%$ or less of myxoid matrix are classified as cellular neurothekeomas; those with more than $50 \%$ are considered myxoid neurothekeomas; values in between are considered intermediate neurothekeomas. ${ }^{1,2,4}$ The three different variants share some histopathologic features: presence of epithelioid and spindle cells with granular eosinophilic cytoplasm; tendency to form multiple small nodules with spiral or fascicular arrangement; association with variable amount of sclerotic collagen; and occasional presence of giant osteoclast-like cells. They may exhibit increased mitotic figures and nuclear atypia. ${ }^{1}$ Myxoid neurothekeo- ma is typically positive for markers of neural origin - such as S-100 protein, GFAP, and NGFR - and negative for macrophage markers such as Ki-M1P and CD-68. The cellular variant is negative for S-100 and positive for NKI/C3, Ki-M1P, and CD-68. Immunohistochemistry suggests that neurothekeomas show differences in their origins: myxoid neurothekeomas would display neural differentiation; the cellular subtype, fibrohistiocytic differentiation. ${ }^{5}$ Neuroectodermal antigens - such as NKI/C3, PGP9.5, and Leu-7 - and fibrohistiocytic antigens - including XIIIa factor, vimentin, EMA, or SMA - have limited diagnostic value in differentiating the subtypes. ${ }^{4}$ S-100 negative myxoid neurothekeoma is rare, with a few cases reported in literature. ${ }^{4}$ Some authors consider that the immunohistochemical profile is more important than histopathology to establish the subtype of the tumor. There are some similar cases reporting cellular myxoid neurothekeoma. ${ }^{4}$ Some authors characterize this variant as a new entity, which features histopathology results typical of neurothekeomas, negative immunohistochemical markers for neural differentiation, and positive results for other markers (such as CD68). ${ }^{4}$ Neurothekeoma treatment consists of the complete excision of the tumors with low recurrence rates. $\left.{ }^{4}\right]$ 


\section{REFERENCES}

1. Fetsch JF, Laskin WB, Hallman JR, Lupton GP, Miettinen M. Neurothekeoma: An Analysis of 178 Tumors With Detailed Immunohistochemical Data and Long-term Patient Follow-up Information. Am J Surg Pathol. 2007;31:1103-14.

2. Navarrete-Dechent C, Curi-Tuma M, Marín C, González S, Sandoval-Osses M. Cellular neurothekeoma: case report and its (un) relation with nerve sheath myxoma. An Bras Dermatol. 2015;90:156-9.

3. Fetsch JF, Laskin WB, Miettinen M. Nerve sheath myxoma: a clinicopathologic and immunohistochemical analysis of 57 morphologically distinctive, S100 protein and GFAP positive, myxoid peripheral nerve sheath tumors with a predilection for the extremities and a high local recurrence rate. Am J Surg Pathol. 2005;29:1615-24.

4. Yun SJ, Park HS, Lee JB, Kim SJ, Lee SC, Won YH. Myxoid Cellular Neurothekeoma: A New Entity of S-100 Negative, CD-68 Positive Myxoid Neurothekeoma. Ann Dermatol. 2014;26:510-3.

5. $\quad$ Stratton J, Billings SD. Cellular Neurothekeoma: analysis of 37 cases emphasizing atypical histologic features. Mod Pathol. 2014;27:701-10.
MAILING ADDRESS:

Yasmin Gama Abuawad

Avenida Ibirapuera, 981

Vila Clementino

04029-000 São Paulo, SP - Brazil

E-mail: yasmin_gama@yahoo.com.br

How to cite this article: Abuawad YG, Saraiva MIR, Westin AT, Valente NYS. S-100 negative myxoid neurothekeoma: a new type of neurothekeoma? An Bras Dermatol. 2017;92(1):153-5. 